\title{
Understanding and managing connected extreme events
}

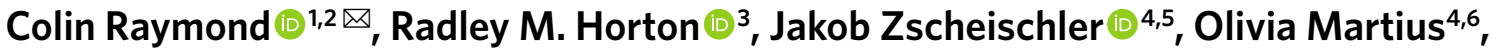 \\ Amir AghaKouchak $\mathbb{1}^{7,8}$, Jennifer Balch ${ }^{9,10}$, Steven G. Bowen ${ }^{11}$, Suzana J. Camargo $\mathbb{1}^{3}$, Jeremy Hess ${ }^{12,13}$, \\ Kai Kornhuber $\mathbb{D}^{3,14}$, Michael Oppenheimer ${ }^{15,16}$, Alex C. Ruane ${ }^{17}{ }^{17}$, Thomas Wahl|18,19 and \\ Kathleen White ${ }^{20}$
}

Extreme weather and climate events and their impacts can occur in complex combinations, an interaction shaped by physical drivers and societal forces. In these situations, governance, markets and other decision-making structures-together with population exposure and vulnerability-create nonphysical interconnections among events by linking their impacts, to positive or negative effect. Various anthropogenic actions can also directly affect the severity of events, further complicating these feedback loops. Such relationships are rarely characterized or considered in physical-sciences-based research contexts. Here, we present a multidisciplinary argument for the concept of connected extreme events, and we suggest vantage points and approaches for producing climate information useful in guiding decisions about them.

n 2017, a parade of severe tropical cyclones devastated the eastern Caribbean, with damages to property and infrastructure that were exacerbated by the consecutive storms ${ }^{1,2}$ and by the depleted response ability of the U.S. Federal Emergency Management Agency stemming from Hurricane Harvey several weeks earlier ${ }^{3}$. A humanitarian crisis ensued in which, predictably, the populations with the highest baseline vulnerability tended to suffer most ${ }^{4}$. In 2018, an exceptionally cold and wet early spring affected winter-cereal harvests and hindered spring planting across Europe, and this, compounded with a hot and dry summer, led to agricultural losses in consecutive cropping seasons-raising wheat and barley prices in the integrated European Union market by $30 \%$ and straining the continent's government and insurance budgets ${ }^{5,6}$.

We term such combinations of extreme events 'connected', to convey the diversity and complexity of interacting physical and societal mechanisms that cause their impacts to be amplified relative to the impacts from those same events occurring separately or univariately (Table 1). Note that this definition includes hazards which result in impacts only or primarily via feedback loops involving anthropogenic systems of some kind. Here, we use 'impacts' to mean the losses arising from the interaction of hazard, vulnerability and exposure (synonymous with consequences or outcomes), and 'risk' to mean potential or unrealized losses, both as defined by the IPCC ${ }^{7}$. Where such a distinction is not necessary, we use 'impacts' as a general term encompassing both concepts.
As further elaborated in Box 1, 'connection' incorporates and builds on the physical-hazard-based framework of 'compound' weather and climate events ${ }^{8-12}$; 'interacting', 'cascading' or 'multi-risk' natural hazards ${ }^{13-18}$; and systemic risks and complexity science ${ }^{19}$. Our discussion is closely informed by advances and assessments in these fields, but homes in on attributes unique to extreme weather and climate events as well as on the exacerbating role that anthropogenic actions can play with regards to both their severity and impacts.

In this Perspective, we describe the broad applicability of the concept of connected extremes and how relevant expertise, disciplinary knowledge and insights inside and outside of academia can best be solicited and employed so applied-science teams that include climate scientists focus on the variables, metrics, locations and temporal aspects of greatest societal importance. We reflect on connected extremes through our research and practitioner experiences in the sectors of food, water, human health, infrastructure and insurance, and show how current risk-management approaches fall short in addressing the complex challenges associated with connected extremes. We then present specific recommendations for how collaborations among the research and decision-making communities may be expanded and enhanced. Consequently, we also aim to inform policies toward the adaptation and mitigation strategies most appropriate for reducing risks from and increasing resilience to connected extremes, which may differ from those designed for single extremes.

\footnotetext{
${ }^{1}$ Earth-Science Division, Jet Propulsion Laboratory/California Institute of Technology, Pasadena, CA, USA. ${ }^{2}$ Department of Earth and Environmental Sciences, Columbia University, New York, NY, USA. ${ }^{3}$ Lamont-Doherty Earth Observatory, Columbia University, Palisades, NY, USA. ${ }^{4}$ Oeschger Centre for Climate Change Research, University of Bern, Bern, Switzerland. ${ }^{5}$ Climate and Environmental Physics, University of Bern, Bern, Switzerland. ${ }^{6}$ Mobiliar Lab for Natural Risks, Institute of Geography, University of Bern, Bern, Switzerland. ${ }^{7}$ Department of Civil and Environmental Engineering, University of California, Irvine, Irvine, CA, USA. ${ }^{8}$ Department of Earth System Science, University of California, Irvine, Irvine, CA, USA. ${ }^{9}$ Earth Lab, CIRES, University of Colorado-Boulder, Boulder, CO, USA. ${ }^{10}$ Department of Geography, University of Colorado-Boulder, Boulder, CO, USA. "Catastrophe Insight Division, Aon, Chicago, IL, USA. ${ }^{12}$ School of Public Health, University of Washington, Seattle, WA, USA. ${ }^{13}$ School of Medicine, University of Washington, Seattle, WA, USA. ${ }^{14}$ Earth Institute, Columbia University, New York, NY, USA. ${ }^{15}$ Woodrow Wilson School of Public and International Affairs, Princeton University, Princeton, NJ, USA. ${ }^{16}$ School of Geosciences, Princeton University, Princeton, NJ, USA. ${ }^{17}$ Goddard Institute for Space Studies, National Aeronautics and Space Administration, New York, NY, USA. ${ }^{18}$ Department of Civil, Environmental, and Construction Engineering, University of Central Florida, Orlando, FL, USA. ${ }^{19}$ National Center for Integrated Coastal Research, University of Central Florida, Orlando, FL, USA. ${ }^{20}$ United States Army Corps of Engineers,

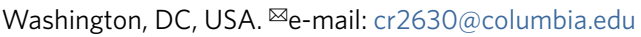


Table 1 | Climate-related hazards with compound physical drivers as well as exacerbating societal drivers

\begin{tabular}{|c|c|c|c|}
\hline Hazard(s) & Climatic drivers & Societal drivers & Refs. \\
\hline Drought & $\begin{array}{l}\text { Precipitation, evapotranspiration, antecedent } \\
\text { soil moisture, temperature }\end{array}$ & Water management, land-use change & $48,49,56$ \\
\hline Physiological heat stress & $\begin{array}{l}\text { Temperature, atmospheric humidity, diurnal } \\
\text { cycle }\end{array}$ & Urbanization, irrigation & 96 \\
\hline Fire risk & $\begin{array}{l}\text { Temperature, precipitation, relative humidity, } \\
\text { wind, lightning }\end{array}$ & Forest management, ignitions & 97,98 \\
\hline Coastal flooding & $\begin{array}{l}\text { River flow, precipitation, coastal water level, } \\
\text { surge, wind speed }\end{array}$ & $\begin{array}{l}\text { Hard infrastructure, removal of natural coastal } \\
\text { barriers }\end{array}$ & 100,101 \\
\hline Flooding at river confluences & $\begin{array}{l}\text { Precipitation, river water levels, large-scale } \\
\text { atmospheric circulation }\end{array}$ & Water management, urbanization & 58 \\
\hline Concurrent heat and drought & $\begin{array}{l}\text { Temperature, precipitation, evapotranspiration, } \\
\text { atmospheric humidity }\end{array}$ & $\begin{array}{l}\text { Water management, soil management, land-use } \\
\text { change }\end{array}$ & 48,49 \\
\hline
\end{tabular}

Examples of how compounding climatic drivers and societal drivers interact to produce connected climate extremes, modified from Table 1 of ref. ${ }^{9}$. The societal drivers listed are non-exhaustive; additionally, only those that contribute directly to the hazard are considered, rather than those that contribute to the impact. Long-term anthropogenic climate change plays into many of these hazards, but is omitted here for simplicity. References are for societal drivers only (for climatic-driver references, see ref. ${ }^{9}$ ).

\section{Physical basis, societal relevance}

Connection between climate extremes can be conceived of as complex time- and space-varying physical and societal mechanisms that relate one event to another (Fig. 1), ultimately causing major impacts (Fig. 2 and Box 1). In the case mentioned in the opening paragraph, a connection was created between the impacts of Hurricanes Harvey and Maria, severe but otherwise unrelated events that occurred $3,300 \mathrm{~km}$ and 26 days apart ${ }^{3}$. Focusing on Hurricane Maria's impacts in Puerto Rico-which included more than 3,000 deaths and nearly US $\$ 100$ billion in damage-post-event reports identified the island's under-maintained infrastructure, limited budget, aging population and territory status as among the factors which contributed to its vulnerability ${ }^{3,4,20,21}$. While the hazards of heavy precipitation and strong winds caused large amounts of direct damage, such as road washouts and drownings, the impacts were exacerbated by slow and patchy relief and recovery efforts. Emergency response systems had been stretched thin by Hurricane Harvey striking Texas the previous month and Hurricane Irma striking Florida the previous week, with administrative mismanagement also coming into play ${ }^{1,4,21-23}$. As summarized by the U.S. Federal Emergency Management Agency (FEMA), "FEMA not only exhausted commodities on hand but also exhausted pre-negotiated contracts to provide meals, tarps, water and other resources during the responses to Hurricanes Harvey and Irma. Therefore, the concurrent response for Hurricane Maria required FEMA to rapidly solicit vendors... increased contract demands from the hurricane season severely taxed FEMA's acquisitions process and contracting personnel..."3. Across Puerto Rico, mortality was highest in isolated municipalities and those with low socioeconomic development, highlighting linkages between vulnerability and impacts ${ }^{21,24}$. The quality and equity of the rebuilt physical systems, reimagined social-support networks and revised decision-making structures will be reflected in future exposure and vulnerability, and most tangibly in the impacts when combinations of extreme events occur again $^{23,25}$.

We argue that these types of complexities mean that successfully parsing, preparing for and responding to connected extreme events requires deep collaboration across sectors and disciplines.
Physical hazards, for instance, are shaped by timing, location and meteorological context, while political, financial, infrastructural and cultural networks make certain combinations of events especially potent from an impacts standpoint, through their exposure and vulnerability characteristics. These networks include traits strongly dependent on governance, culture, historical precedent, information flow and other legacies-'societal mechanisms' that are ever-changing and that can create systemic risks when interconnections result in fragility rather than resilience ${ }^{19,26,27}$, due to internal dynamics or external influences such as climate change.

In this context of intrinsic interdisciplinarity, shifting relationships and capacity for surprise (such as the crossing of tipping points $)^{28}$, joint physical-societal assessments are critically important for building scientific understanding and improving risk management in response to connected extremes. Moreover, adaptation strategies are ever-evolving under a changing climate ${ }^{29}$, requiring iterative efforts to evaluate their efficacy ${ }^{30}$. Not only must risks be identified, monitored and evaluated, but the risk-management process itself must be subject to reframing and transformation to match the risks (or state of knowledge of them). Greater severity and frequency of many hazards as a result of climate change, combined with a lower loss threshold in populations with higher vulnerability, makes such efforts especially urgent.

\section{Societal impacts of connected extremes in five major sectors}

In this section, we provide examples of concepts and methods regarding connected extremes through the lens of five sectors reflecting our research and practitioner expertise: food, water, human health, infrastructure and insurance. We discuss (1) how each sector is affected, (2) current responses and their effectiveness and (3) important types of knowledge that new decision-relevant collaborations could produce.

Food. The agricultural sector consists of a multitude of heterogeneous farming systems and complex networks of food supply, demand and trade that exhibit high systemic risk ${ }^{31}$. In this context, connected extremes can threaten regional and global food security. 


\section{Box 1 | Connected extremes definition and conceptual framework}

\section{Defining connected extreme weather and climate events}

Compound weather and climate events are comprised of multiple distinguishable physical drivers and/or hazards and their risks. These can be subdivided according to the primary means of interaction: temporal compounding (for example, a sequence of storms), spatial compounding (for example, synchronous crop failures), preconditioning (for example, rain-on-snow flooding) and concurrence of multiple variables (for example, storm surge, pluvial flooding and high winds from a single storm). Details on these categories can be found in ref. ${ }^{8}$.

The concept of connected extreme weather and climate events further recognizes that compound event impacts are often substantially and nonlinearly influenced by non-physical factors such as exposure and vulnerability, cutting across sectors and scales (from personal to society wide). These 'societal mechanisms' can tie together the impacts from two or more climate extremes, whether due to resource constraints (for example, exhaustion of an insurance fund or pool of emergency responders), health considerations (for example, power outages or medication-supply-chain disruptions) or other linkages (Fig. 1). Other possible longer-term feedbacks range from changes in risk pricing to wholesale rethinking of risk-management strategies ${ }^{30}$, which in Fig. 1 are compressed into the 'Response' category. Whatever their nature, connections' meaningfulness lies in their robustness and traceability, terms which can best be defined by the stakeholders involved.

It is the creation or strengthening of the connections between events, in the impacts space and involving anthropogenic systems, that leads to our terminology of 'connected' events as being distinct from 'compound' events, and also from interacting-risk or multi-risk frameworks that focus on combinations of physical hazards ${ }^{13}$.

\section{A challenge of 'spaces'}

One framework for understanding the research and decisionmaking issues associated with connected extremes is to view them as resulting from a mismatch between the planning and response decisions that would be achieved by conventional methods (the 'decision space') and those that would optimally address the full set of physical possibilities (the 'event space') (Fig. 3). Many organizations are constrained to make decisions within a narrow spatiotemporal domain, leading to conflicting decisions at one scale versus another. A small city with a limited budget (represented by Actor 1 in Fig. 3) or a government agency with a specific mission cannot be expected to have the capacity to coordinate across multiple spatial scales to optimally plan for or respond to multivariate or sequential connected extremes which fall only partially under its purview, much less spatially compounding extremes like river flooding caused by conditions upstream. Additionally, physical processes and data availability make the event space difficult to reliably estimate-a confounding uncertainty when trying to reach a decision under political, financial and technical constraints ${ }^{95,112,113}$.

Major wildfires, for instance, are often 'connected' in several ways $^{97}$. Actors such as city departments, national agencies, private landowners, insurers, corporations and non-profits must decide how to manage long-term fire risk, emergency responses and recovery, including decisions about how and where to reinvest. Each of these spheres of action is guided by (1) the size and mandate of the decision makers, which defines their mission and hence affects their quantity of resources; (2) their ability and/or incentive to distribute risk; and (3) the political expectations or regulatory requirements under which they operate. These diverse incentives and restrictions complicate efforts to plan and execute a holistic response that does not, for example, merely delay the risk or transfer it to other sectors ${ }^{95}$. Hence, understanding this patchwork of 'decision spaces' can aid in characterizing the type of decision-relevant knowledge that research on connected extremes should aim to generate. Social scientists, risk managers and boundary-spanning organizations are indispensable here, by helping to build and leverage communication networks that can delineate the feasible intersection of the decision and event spaces.
Crops are particularly vulnerable to multivariate hot and dry events that cause water stress, while workers and livestock are burdened by hot and humid extremes that cause physiological stress $^{32,33}$. The sequence in which extremes occur can exacerbate overall impacts, given crop physiologies and the need for particular field conditions during key developmental stages ${ }^{34}$. Early-season floods can delay field preparation and planting, pushing back crop calendars in a manner that exposes crops to late-season frost or drought stress. Early wet conditions may also weaken plants' ability to cope with subsequent extremes by limiting their root depths or creating conditions favourable for pest infestations. Alternatively, early-season drought can cause farmers to deplete water resources and thus increase vulnerability to dry spells later in the season.

Currently, some crop models analyse water, nitrogen and heat stress on each day and apply only the largest stress factor, missing the compound nature of many hazards. Conditional effects are also challenging for statistical crop-model yield projections, which, for maximal accuracy, would require incorporation of the timing of extreme events as well as of cross-terms that identify sequential connections between early- and late-season extremes of different variable types ${ }^{35}$.

The confluence of all these issues is crystallized in considering the prospect of a multiple-breadbasket failure, with extreme events striking two or more important agricultural production zones, resulting in a large aggregate effect on global food production and prices $^{36,37}$. Such a situation could result from independent regional extremes randomly co-occurring, or could have a correlation structure driven by teleconnections linked to major modes of climate variability ${ }^{38,39}$. Recent decades have seen a consolidation of global production into fewer regions and a proliferation of monoculture systems, increasing the potential for a small number of synchronous regional-scale extremes to have widespread impacts ${ }^{40}$. Agricultural trade models connect regional production into wider balances of supply and demand to achieve long-term equilibria; however, year-by-year actions of stakeholders along the value chains from field to global market and from global market to supermarket shelf are not as well-simulated, hindering resilience planning to 'shocks' such as those that connected extremes can induce.

To prevent food system shocks, there is a great need for enhanced understanding of the impacts of specific sequences of extreme events at a local scale, particularly if risks could be identified early enough to allow for appropriate farming and trading countermeasures. Complementarily, connections between extremes in the food context often manifest through non-farm elements such as transport and processing, so incorporating this systems knowledge when designing climate research-even if only as an initial consideration -would significantly improve its usefulness.

Water. Access to clean water in sufficient quantities is a fundamental requirement for human societies. In a growing and urbanizing 
a

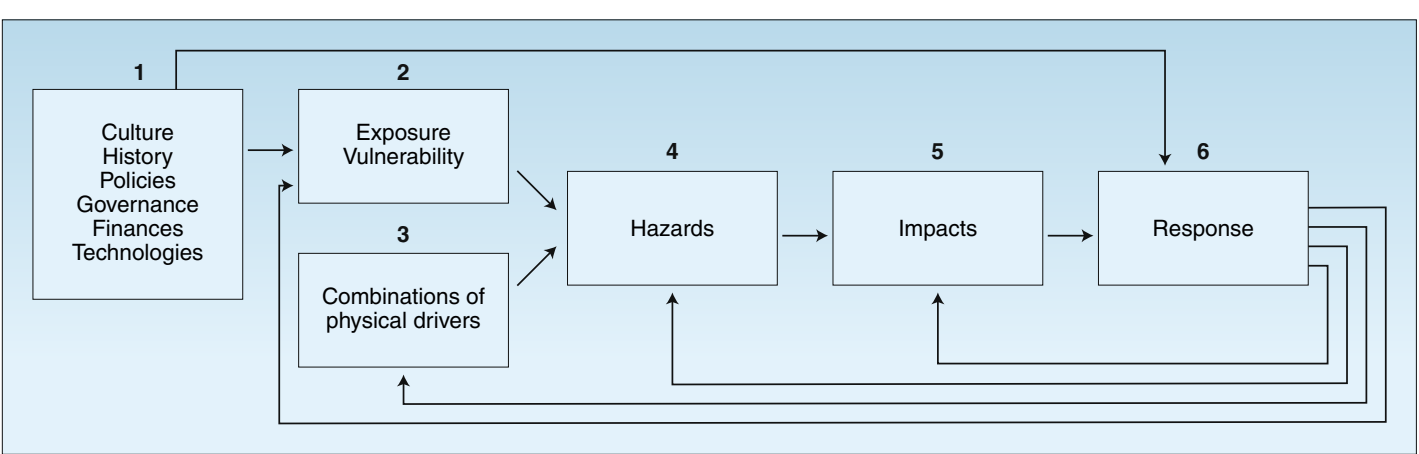

b

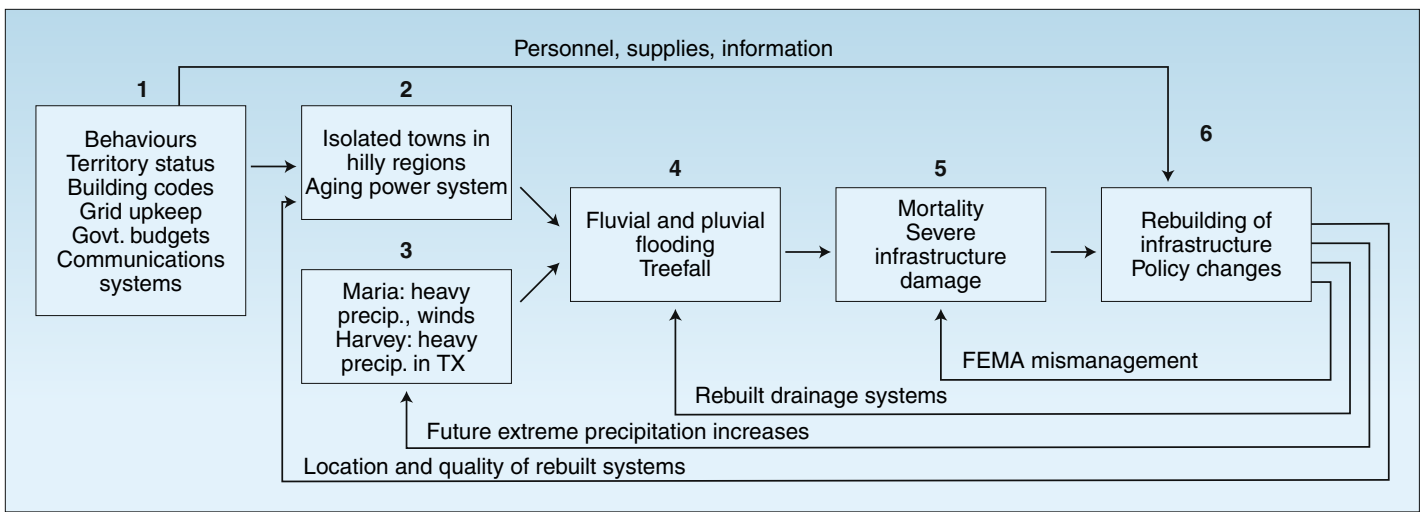

Fig. 1 | The flow of connected extremes. a, Generalized diagram of the interactions among physical and societal drivers that constitute connected extreme events. Boxes 2 and 3 together represent 'risk', as defined in the text. b. An illustration of a for the case of Hurricane Maria impacting Puerto Rico in 2017 following a sequence of severe tropical cyclones in the Caribbean and Gulf of Mexico. For simplicity, only one or two examples in each category are presented. Box 1 highlights behaviours ${ }^{110}$, territory status ${ }^{20}$, building codes $^{4}$, grid upkeep ${ }^{4}$, government budgets ${ }^{3}$ and communications systems ${ }^{4}$. Box 2 highlights isolated mountain town ${ }^{21}$ and the aging power system ${ }^{20}$. Box 3 highlights Hurricanes Maria' and Harvey ${ }^{111}$. TX, Texas. Box 4 highlights flooding and treefall ${ }^{21}$. Box 5 highlights mortality ${ }^{21}$ and infrastructure damage ${ }^{4}$. Box 6 highlights rebuilding of infrastructure ${ }^{20}$ and policy changes ${ }^{4}$. Arrows indicate FEMA mismanagement ${ }^{22}$, rebuilt drainage systems ${ }^{25}$, future extreme-precipitation increases ${ }^{111}$, location and quality of rebuilt systems ${ }^{4}$, personnel, supplies and information ${ }^{23}$.

world, water management and distribution are challenging but unavoidable tasks, especially when both critical water states-flood and drought — can result from a combination of physical drivers and can be exacerbated by correlations among them ${ }^{41,42}$.

Compounding effects can alter flood risk in several distinct ways. Antecedent conditions, such as groundwater or soil moisture, often play a key role in flood generation ${ }^{10}$. Concurrent flood drivers can be of the same type, such as discharge at river confluences ${ }^{43}$, or different types, such as the superposition of high tides, storm surges, waves and freshwater inflow leading to extreme total water levels along coastlines ${ }^{44,45}$. Both spatial and temporal compounding play into the severity and impacts of high- and low-water events and, consequently, the outcomes of hydrological risk assessments ${ }^{46,47}$. Analogously, droughts are inherently multivariate phenomena that respond nonlinearly to changes in controlling parameters, such as temperature, precipitation and soil moisture ${ }^{48-50}$. Furthermore, drought impacts are often largest when they compound temporally and spatially, termed 'mega-droughts ${ }^{51}$, and it is these situations when interactions with other hazards such as heat waves are strongest ${ }^{52}$.

The problem of interconnected hydrological drivers has prompted many advances in statistical methods for compound events, including copulas and scenario modelling (Table 2) (15,53 $^{\text {. One }}$ insight these have revealed is that, for droughts as well as floods, changes in the correlation structure between drivers can alone lead to large changes in extreme events ${ }^{54,55}$. Acting on this awareness, agencies such as the U.S. Army Corps of Engineers have begun accounting for correlations between river discharge and storm surge when planning coastal projects. The Corps is also assessing the effects of sequential droughts and floods on reservoir operations, and of post-fire precipitation on reservoir sedimentation.

Anthropogenic systems interact with the natural environment to direct and shape the ultimate impacts of extreme hydrological events. For example, urban drainage systems modulate both the amount of surface flooding and the water quality at discharge points, due to the correlation of combined sewer overflows with heavy precipitation. In exceptional droughts, reservoirs used primarily for water supply, flood mitigation or power generation may actually worsen water shortages and thereby tensions between different regions or water users ${ }^{56}$. These physical-societal dynamics lead to uncertainties in water scarcity projections even larger than the corresponding uncertainties in precipitation ${ }^{57}$. Actions taken during an event can often represent an additional layer. During the spring 2011 Mississippi River floods driven by heavy rain and snowmelt across the U.S. Upper Midwest, multiple spillways were opened (as designed) to protect downstream urban areas, resulting in some flooding of agricultural lands ${ }^{58}$. Similarly, storm-surge barriers prevent ocean-side flooding when closed but can worsen wave impacts on the seaward side while simultaneously causing freshwater to accumulate on the landward side, affecting areas that might not otherwise have been at risk, especially when rainfall-driven river discharge is also high ${ }^{59}$.

For both types of hydrological extremes, decisions made throughout a region have physical and behavioural consequences which tend to accumulate over time and then prominently manifest when waterbecomesscarceoroverabundant. Theneed tobetter understand and account for the joint distribution of physical drivers and 


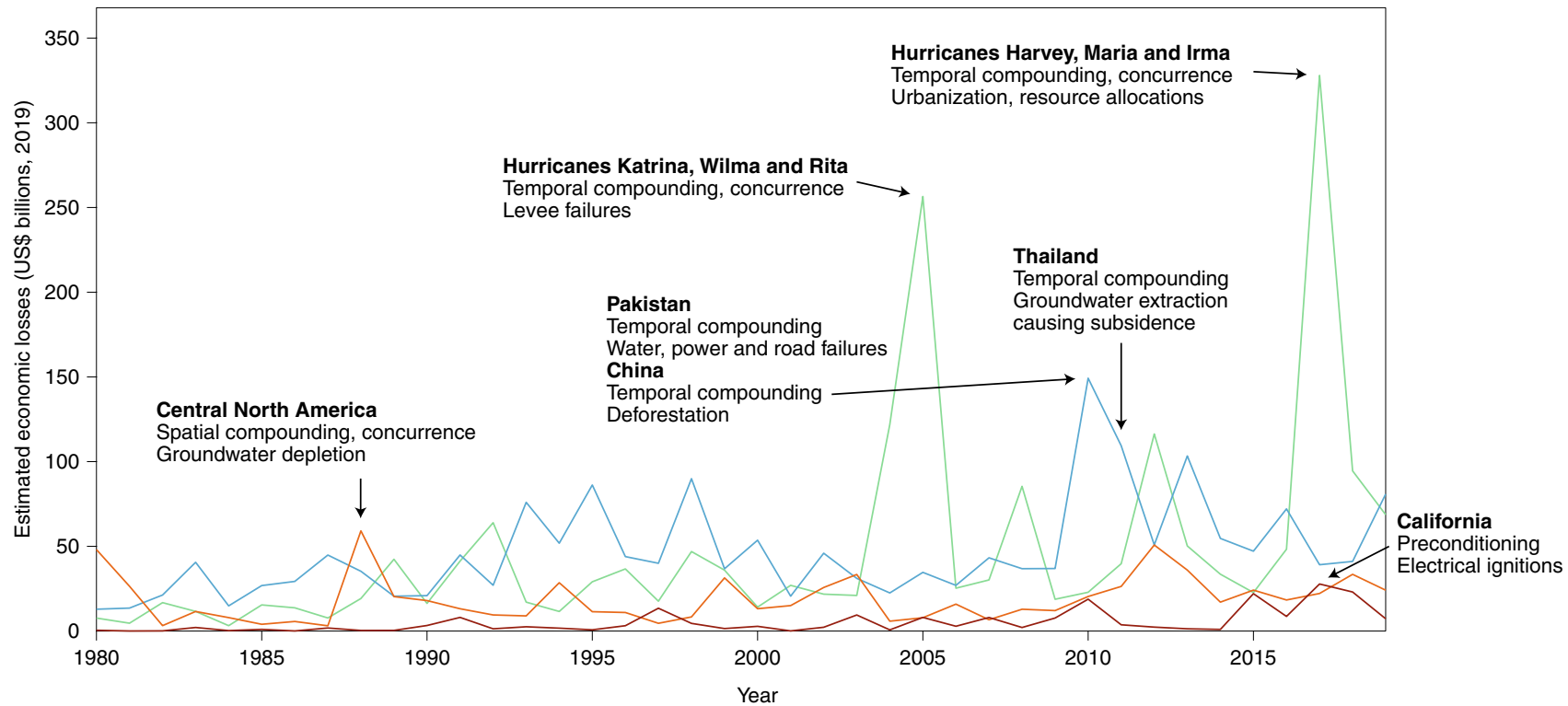

Fig. 2 | Major losses caused by extreme climate events over 1980-2019 and their connective elements. Lines trace the annual global sum of estimated economic losses caused by tropical cyclones (green), floods (blue), droughts (orange) and wildfires (red). Annotations indicate the largest events in high-loss years followed by several of the (first row) physical and (second row) societal drivers that shaped the total impacts. Economic-loss data are from Aon, Catastrophe Insight Division.

societal mechanisms warrants close collaboration between social scientists, engineers, hydrologists, climate scientists and water agencies -encapsulated by the relatively new field of socio-hydrology ${ }^{60}$.

Health. Population health is a function of a wide set of determinants, including interactions with multiple environmental factors over time ${ }^{61}$. Where, when and which populations are exposed to connected extremes are all strong predictors of the severity of impacts ${ }^{62}$. Additionally, demographic vulnerability is itself often multivariate and temporally compounding ${ }^{63}$. For these reasons, an integrated health perspective-considering wealth, insurance, housing, food security and other essentials-is gaining traction among researchers and practitioners. This evolution makes the connected extremes framework a natural one.

In the healthcare context, important types of compounding include multivariate extremes-including heat-and-humidity as well as heat-and-air-quality events ${ }^{33,64}$-and temporal compounding, on timescales ranging from hourly-to-daily (for emergency response) to subseasonal-to-seasonal (for preventative campaigns, supply-chain planning and recovery efforts). For extreme heat, diverse health hazards will very likely interact more frequently as the recovery time between heat waves shrinks, making it a prototypical instance of a connection between extreme events enhanced by climate change ${ }^{65}$. Other societal drivers such as power outages, whether resulting directly from physical drivers ${ }^{66}$ or induced to prevent poorly maintained equipment from sparking wildfires during compound wind and low-humidity events (such as in the 2019 California fire season), can also feed back onto health outcomes. These examples underscore how human decisions made over decades modulate the health impacts of extreme events on much shorter timescales.

Both knowledge and capacity for action pose challenges with regards to the impacts of connected extreme events on the health sector. Many epidemiological analyses take limited advantage of sophisticated methods for modelling these types of complex risks. Additionally, from the operational point of view inherent to healthcare delivery, the motivation to adopt new tools and methods-and to follow through on the ensuing recommendations-can be low in the face of everyday demands, a lack of dedicated personnel, limited utilization of system modelling and difficulties with funding for structural change. Health systems are diversely organized around the world, with varying but typically limited coordination, information sharing and inter-sector collaboration ${ }^{67}$. Although enhanced integration of disaster risk reduction, disaster preparedness and disaster response has the potential to manage risk more effectively, these activities remain somewhat tenuously linked, with the result that the health sector is sometimes overwhelmed by the impacts of connected extremes such as Superstorm Sandy (which was followed by a cold Nor'easter) or Hurricane Maria. In these cases, personnel are not efficiently deployed, supply chains are disrupted and suboptimal health outcomes are achieved. Such crises have also spurred improvements in organization and communications ${ }^{68,69}$.

This situation creates an outsize need for improved quantification of and communication about connected extremes with major potential health impacts, coordinated to align with and inform specific procedural choices. For instance, while there have been some efforts to systematically examine how connected extreme events may impact health systems ${ }^{70}$, much more could be done to determine where and how connected extremes may result in unanticipated impacts, such as by drawing on past experiences ${ }^{71}$. The health sector could benefit from examples of how other sectors have anticipated impacts and incorporated this learning into reforms.

Infrastructure. Critical infrastructure includes systems that provide energy, water, food, transport and security. Connected extremes can exert forces on these systems beyond their design specifications, making it imperative to understand and incorporate such effects into infrastructure planning and risk assessments. The relevant interactions are typically poorly constrained, despite the large investments involved, due to the great complexities of the systems and the numerous and widely disparate actors with jurisdiction over them.

Large wildfires and tropical cyclones-themselves sometimes compound events-frequently cause flooding, slope failures and vegetation blowdown which, in combination with vulnerable infrastructure, can impede emergency response efforts and post-disaster rebuilding ${ }^{4,72}$. Such situations may also create unanticipated 


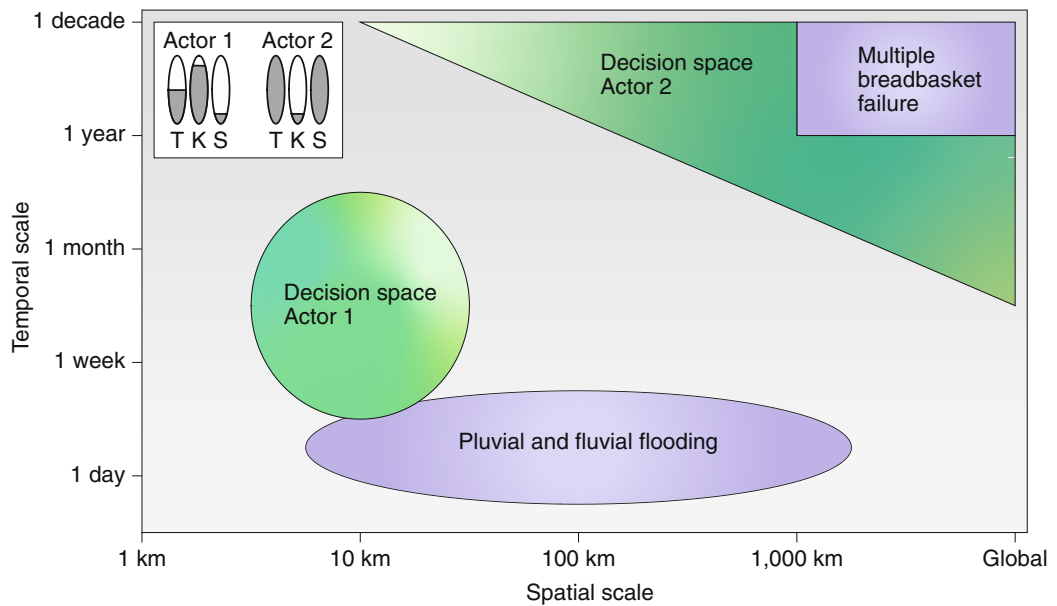

Fig. 3 | Decisions related to multiscale connected extremes. Generalized diagram of the spatiotemporal scales associated with connected extremes (across both physical and societal aspects) compared against the typical spatiotemporal scales of the decision-making that affects the societal response to them, for two example events and two example actors. The meters for each actor indicate their (hypothetical) relative characteristics in terms of technical capability ( $T$ ), cultural or political capital $(K)$ and financial or geographic size (S). High meter readings correspond to a capacity for broad, complex, long-term and expensive actions, whereas low meter readings correspond to a necessity for taking localized, simpler, short-term and less-expensive actions.

additional hazards, such as major traffic jams ${ }^{73}$. Well-designed infrastructure can exhibit strategic purposeful failures which nonetheless result in property damage or loss of life, as in the Mississippi River flood example discussed above. Emergency response and rebuilding efforts may be particularly vulnerable to sequences of extremes, such as a heat wave following a hurricane- ${ }^{66}$ or wildfire-induced power outage.

Infrastructure decisions (investment, maintenance and outreach) play a key role in connecting extremes, especially for the most exposed or vulnerable communities. During the Thailand floods of 2011, politically motivated decisions on how to route water resulted in the protection of central Bangkok at the expense of peripheral areas, where major manufacturing facilities were located ${ }^{74}$. The resulting floods caused large economic losses in Thailand and globally due to supply-chain disruption that played out over the following months. At the dry end of the spectrum, the pre-emptive California power outages mentioned above were deemed necessary due to overgrown vegetation and aging equipment in addition to severe fire weather.

As a result, there is increasing adoption of systems thinking for infrastructure ${ }^{3,4}$ - considering each subsystem's design, management and interconnections-but this requires climate information of sufficient detail and reliability to be optimally employed. The interactions described here highlight the necessity for more collaboration at the interface between natural sciences, engineering and social sciences to enable policy choices that are well-informed, robust and equitable over the typically long lifetime of an infrastructure project.

Insurance. Insurance plays an integral role in risk management and disaster recovery for diverse sectors and at scales ranging from personal to global. However, emerging spatial correlations across multiple hazards of the same or different type could, if unrecognized, pose a systemic risk to (re)insurers and the broader economy.

Humanitarian and property impacts from large-scale disasters with multiple drivers (for example, heat and drought leading to wildfires) or multivariate hazards (for example, wind and water for tropical cyclones, or wind, hail and water for severe convective storms) can be extremely costly (Fig. 2). The earlier examples of Hurricanes Harvey and Maria in 2017, and the simultaneous California wildfires in 2017 and again in 2019, are illustrative. The complexities associated with recognizing and responding to such perils are amplified when the regions affected are underinsured and/or repeatedly exposed ${ }^{75-77}$. Additionally, the global 'protection gap'-the portion of the economic cost of disasters not covered by insurance-is still a concern for increasingly at-risk regions within Latin America, Africa and Asia ${ }^{78}$. Health insurance coverage, likewise, is strongly correlated with sociodemographic factors, creating another source of inequality and population vulnerability.

The catastrophe models commonly used in the insurance industry are limited in their ability to see connected multihazard events 'over the horizon' because they are calibrated using observed or synthetically generated event sets and portfolio exposures. Event types that are known to be possible but considered highly unlikely (called 'grey swans') are not well-captured in this framework, precluding proper risk quantification. Even when connected extremes are able to be represented, interpreting and acting on this knowledge remains challenging for (re)insurers.

The overall risks associated with large, volatile, multivariate extreme-event impacts make it essential for (re)insurers and businesses to make decisions based on an accurate evaluation of the hazards, which often means understanding the full spectrum of impacts of extreme events and also the potential connections between them. Indeed, such connections may even threaten the continued economic viability of corporations, insurers and utilities that do not sufficiently investigate them and act on this knowledge. The need to properly incorporate long-term vulnerabilities from factors such as climate change and socioeconomic shifts poses a major challenge to a business model where contracts are typically revised on an annual basis and are thus inherently short term. As climate change progresses, assumptions regarding probabilities of extreme events will need to be periodically updated, and changes in exposure and infrastructure vulnerability will need to be accounted for. Analyses and policies dependent on such updates will necessarily contain greater uncertainty, with a smaller (or non-existent) comparable historical record to refer to. Further collaborations that leverage the statistical expertise and computational power of (re)insurers and the scientific understanding and techniques of climate researchers have large potential to illuminate this future more clearly ${ }^{79}$.

\section{Quantitative and conceptual methods}

Considering societal attributes and response capacities in addition to climate factors and traditional impact models is a daunting 
Table 2 | Methods for investigating connected extreme events and their impacts

\begin{tabular}{|c|c|c|c|c|}
\hline Statistical approaches & Description & Strengths & Weaknesses & Refs. \\
\hline Copulas & $\begin{array}{l}\text { Characterize dependence } \\
\text { among multivariate physical } \\
\text { hazards or drivers }\end{array}$ & $\begin{array}{l}\text { Common and well-developed, } \\
\text { straightforward to apply }\end{array}$ & $\begin{array}{l}\text { Limited data can make fitting } \\
\text { difficult, do not identify causal } \\
\text { relationships }\end{array}$ & 53,102 \\
\hline Modelling approaches & Description & Strengths & Weaknesses & Refs. \\
\hline Large climate model ensembles & $\begin{array}{l}\text { Physical models produce } \\
\text { thousands of years of } \\
\text { simulations }\end{array}$ & $\begin{array}{l}\text { Large sample size can include } \\
\text { directly modelled rare events } \\
\text { beyond those in the historical } \\
\text { record }\end{array}$ & $\begin{array}{l}\text { Model representations of extreme } \\
\text { events and inter-relationships may } \\
\text { not be accurate }\end{array}$ & 105 \\
\hline Integrated assessment models & $\begin{array}{l}\text { Model a wide range of } \\
\text { societal impacts resulting } \\
\text { from climate-related risks }\end{array}$ & $\begin{array}{l}\text { Incorporate many sectors and } \\
\text { interactions }\end{array}$ & $\begin{array}{l}\text { Generally have coarse spatial } \\
\text { resolution and simplified } \\
\text { interactions (for example, no } \\
\text { two-way feedbacks) }\end{array}$ & 108 \\
\hline Socio-physical approaches & Description & Strengths & Weaknesses & Refs. \\
\hline Adaptive pathways & $\begin{array}{l}\text { Explore specific possible } \\
\text { futures and sequences of } \\
\text { adaptation responses }\end{array}$ & $\begin{array}{l}\text { Allow for policy planning } \\
\text { despite uncertainties of future } \\
\text { climate change }\end{array}$ & $\begin{array}{l}\text { May require many assumptions } \\
\text { about future pathways }\end{array}$ & 80,109 \\
\hline Storylines and scenario planning & $\begin{array}{l}\text { Explore sequences of events, } \\
\text { impacts and associated } \\
\text { decisions independent of } \\
\text { probability }\end{array}$ & $\begin{array}{l}\text { Enable identification of } \\
\text { high-impact combinations } \\
\text { of events that probabilistic } \\
\text { assessments might miss }\end{array}$ & $\begin{array}{l}\text { May require many assumptions } \\
\text { about future scenarios }\end{array}$ & 71,82 \\
\hline
\end{tabular}

A selection of methods relevant for connected extreme events and their impacts, representing a snapshot of the diversity of each type of approach. References are intended to provide a guide as to how the methods are used. In many cases, a combination of different methods is necessary to understand the drivers, impacts and future projections of connected extreme events.

challenge. However, targeted methodologies informed by the particular type or location of impact can begin to decompose the complexity and diversity of connected extremes. Some uncertainties surrounding the 'event space' of connected extremes can be confronted with techniques aimed at constraining the underlying compound physical drivers. We note a selection of these from the climate literature in Table 2 under 'Statistical approaches' and 'Modelling approaches', and refer interested readers to refs. ${ }^{8,13}$ for a more complete description.

Disentangling the physical-societal interactions that characterize connected extremes, in contrast, requires highly flexible and less quantitative methods to ensure usability and robustness in the face of deep and complex uncertainties (Table 2; see the section titled 'Socio-physical approaches'). For instance, the adaptive pathway approach $^{80}$ recognizes that the 'decision space' can be highly sensitive to climate change, political or financial resources, or other contexts, and may exhibit qualitative jumps at certain 'tipping point' thresholds ${ }^{81}$. Storylines and scenario-planning methods about potential large-impact events allow for the engagement of stakeholders and the public in identifying crucial factors, chains of causality and 'tail risks' through a collaborative process unencumbered by the usual focus on quantification ${ }^{71,82,83}$. Stress testing explores the 'impacts space' associated with connected extremes' imprint on a given sector or location, highlighting where impact sensitivities are largest in response to slight changes in physical drivers ${ }^{84,85}$.

In general, these approaches lead to fewer but more reliable conclusions than conventional climate impacts studies, especially for connected extremes with little or no precedent. Being non-probabilistic, they require careful evaluation by sectoral experts to interpret their outcomes. However, critical test levels can be associated with societal mechanisms, such as supply chains, enabling assessment of the type and severity of extremes that could plausibly cause important disruptions. Specific types of model validation and improvement which could further inform the study of connected extremes include incorporating memory of how previous extremes have affected risk through the depletion of resources, divergence of development pathways, degradation of vulnerability or alteration of exposure, and also better accounting for systemic connections between regions and/or sectors through markets, resource pools or decision-making frameworks.

True coalescence around shared definitions, best practices and research priorities can only occur through sustained and in-depth conversations where sector experts, stakeholders, policymakers and practitioners meaningfully shape the research process from conceptualization to results to implementation. This process has been described by many terms, including 'co-production' ${ }^{86,87}$, 'joint 
problem formulation'88, 'co-development ${ }^{89}$, 'design thinking' ${ }^{90}$ and "bottom-up approaches" ${ }^{\prime 1}$. The underlying principles are consistent: to identify critical constraints and interactions (from ethnography, expert solicitation, process-based impact models and/or systems analysis), and then to use these to iteratively formulate the questions that guide systematic study of the climate. In our view, connected extreme events are too idiosyncratic to allow for a prescribed 'best' approach a priori.

\section{Expecting the unexpected}

Thorough investigation of connected extremes is often limited by the quantity and type of suitable historical data and model simulations, for both drivers and impacts. For example, variables that play key roles in modulating many connected extremes (for example, wind speed and humidity) are not widely observed at fine temporal resolutions and have short periods of record, but would greatly aid in observational analyses and model validations. In some regions, this problem includes core variables, such as precipitation. Essential vulnerabilities and interactions between decision-making entities remain exogenous to most assessments of climate extremes or are not well characterized at all, leading to uncertainties as basic as the primary cause of impacts from historical connected extremes. Qualitative identification of connections can similarly be limited by data availability. Resolving such questions would aid in building overall confidence about how extreme impacts develop: which systems break down, why, and who is affected when that happens.

The need for skilful forward-looking assessments is underscored by the rapidity of projected twenty-first century warming, which will result in historical conditions always providing incomplete information on the contemporaneous range of possibilities $^{12}$. Therefore, the coming decades will no doubt see previously unanticipated or newly important combinations of extremes ${ }^{66}$. Additionally, risk relationships may change in a qualitative way, such as the emergence of summertime drought-heat interactions in historically cool-summer regions ${ }^{52}$ or the increased risk of compound flooding due to sea-level rise ${ }^{45}$. Stretching the 'event space' in this way may result in cultural, economic, ecological and/or technological responses that reciprocally shape exposures, vulnerabilities and, perhaps, the anthropogenic forcing itself ${ }^{91,92}$.

Climate-system knowledge that provides information about poorly constrained risks from connected extreme events is crucial in helping determine the range of necessary actions. Communication about such scenarios could be key for mobilizing all sectors of society to consider their interfaces with other sectors and the ways in which these interactions cause them to be at risk from connected extreme events. Tools and frameworks for assessing these risks could therefore aid in making increasingly severe connected extreme events a central part of the overall climate change discussion, including via financial and legal mechanisms ${ }^{93}$.

\section{Conclusions and recommendations}

The complex and contingent nature of connected extreme events causes them to possess several attributes distinct from those associated with isolated or univariate extreme events. These include a large, poorly characterized sensitivity to small changes in mean climate conditions and a low availability of data on important physical and societal characteristics. Together, these lead to a heightened risk of crossing unknown tipping points in terms of response capacity. Because connection between extreme events depends heavily on situational factors such as season, location and groups affected, essential ingredients for making progress in addressing them include careful impacts-oriented analysis, usage of higher-order metrics and collection of high-quality, high-resolution impacts data. This is an area where the power of emerging computational and communication technologies is likely to be keenly felt.
We consider the climate science community's role as designing the research-side companion element to the critical decision-making challenges associated with connected extremes ${ }^{81}$, ensuring that scientific information is provided in a way that is congruent to existing decision-making pathways ${ }^{86,94}$. The bounds of the 'decision space' may significantly shape the roles of scientists and decision makers: problems with long-term aspects or a wide range of potential policy solutions are most likely to be usefully informed by climate research, while actions with a narrower scope and sensitive cultural or political considerations are weighted toward decision makers.

To the extent possible, collaborations should include determining major feedbacks between physical processes and societal decisions that most affect the final impact. Stated differently, impacts can serve as a winnowing device to identify what combinations of extreme events matter. This knowledge gathering can also incentivize the selection of a more effective mix of policies, including robust or flexible adaptation strategies that provide benefits under a range of connected climate and impact outcomes, by better foreseeing relevant societal and environmental changes over the timescale of the investment $^{91}$. The COVID-19 pandemic represents a dramatic object lesson in how unprecedented events can create or exacerbate correlated risks related to both climatic and non-climatic stressors, amplifying impacts but offering opportunities for shared learning and long-term resilience. Lastly, impacts-driven research efforts can reveal particular disciplines where the presence of specialists would be especially valuable-there is the potential for fruitful exchanges to take place between researchers in the climate domain and experts in engineering, statistics, health, urban planning, sociology, psychology, finance, ecology and emergency management, among others. It is often only through such detailed conversations that essential incentives and constraints come to light and that conceptual paradigms shift ${ }^{95}$.

Most broadly, we argue for promoting mechanisms to recognize the components of a connected extreme event as such, and to gather and share important information about them to facilitate risk management across all levels of decision-making. At a recent workshop, few participants knew of any examples in which connected extremes had been included in planning guidelines. This communication barrier also exists within the physical science community, where examples emerged of certain genres of events (for example, local situations) for which the necessary resources have not yet been marshalled to examine the connectivity or full implications as might be seen when looking through a wider lens. The strong modulation of the impacts of connected extremes via complex societal systems demands serious and sustained efforts to facilitate geographic and cross-domain knowledge exchange, such that climate research results can lead to well-informed pre-event preparation and post-event recovery, ultimately aiding in the amelioration of the serious impacts that connected extremes often produce. Facing this challenge, some encouragement might come from the analogous example of aviation, where physical science, engineering and social sciences have come together to successfully mitigate-despite greatly increasing system complexity-the frequency of disastrous failures, which tend to result only from the concatenation of many low-probability events.

\section{Data availability}

Data used in Fig. 2 are available from the corresponding author upon reasonable request. The data are not publicly available as they are part of a commercially proprietary dataset.

\section{Code availability}

Code for reproducing Figs. 2 and 3 has been archived at https://doi. org/10.5281/zenodo.3714226.

Received: 21 November 2019; Accepted: 23 April 2020;

Published online: 15 June 2020 


\section{References}

1. Klotzbach, P. J. et al. The extremely active 2017 North Atlantic hurricane season. Mon. Weather Rev. 146, 3425-3443 (2018).

2. Murakami, H., Levin, E., Delworth, T. L., Gudgel, R. \& Hsu, P.-C. Dominant effect of relative tropical Atlantic warming on major hurricane occurrence. Science 362, 794-799 (2018).

3. 2017 Hurricane Season FEMA After-Action Report (FEMA, 2018); https:// www.fema.gov/media-library/assets/documents/167249

\section{Details the timeline of actions by the US Federal Emergency}

Management Agency in the lead-up and aftermath of Hurricanes Harvey and Maria in 2017, including underlying decision-making parameters.

4. Transformation and Innovation in the Wake of Devastation: An Economic and Disaster Recovery Plan for Puerto Rico (Government of Puerto Rico, 2018); http://www.p3.pr.gov/assets/pr-transformation-innovation-plancongressional-submission-080818.pdf

5. Short-term Outlook for EU Agricultural Markets in 2018 and 2019. Report No. 22 (European Commission, 2018); https://ec.europa.eu/info/sites/info/ files/food-farming-fisheries/farming/documents/short-term-outlook-autumn2018_en.pdf

6. Faust, E. \& Strobl, M. Heatwaves, Drought and Forest Fires in Europe: Billions of Dollars in Losses for Agricultural Sector (Munich Re, 2018); https://www.munichre.com/topics-online/en/climate-change-and-naturaldisasters/climate-change/heatwaves-and-drought-in-europe.html

7. Oppenheimer, M. et al. in IPCC Climate Change 2014: Impacts, Adaptation, and Vulnerability (eds Field, C. B. et al.) 1039-1099 (IPCC, Cambridge Univ. Press, 2014).

Defines the terms 'hazards', 'exposure' and 'vulnerability', and provides a consensus framework for how these factors combine to shape risk, including examples and assessment paradigms.

8. Zscheischler, J. et al. A typology of compound weather and climate events. Nat. Rev. Earth Env. https://doi.org/10.1038/s43017-020-0060-z (2020). Reviews key concepts and methodologies for compound extreme weather and climate events, and proposes a classification scheme to unite analyses across scales and event types.

9. Zscheischler, J. et al. Future climate risk from compound events. Nat. Clim. Change 8, 469-477 (2018).

10. Wahl, T. et al. When environmental forces collide. EOS https://doi. org/10.1029/2018EO099745 (2018).

11. Leonard, M. et al. A compound event framework for understanding extreme impacts. WIREs Clim. Change 5, 113-128 (2014). Describes the motivation for the concept of compound weather and climate events, and proposes a graphical and statistical analysis framework that hinges upon stakeholder input.

12. Seneviratne, S. I. et al. in Managing the Risks of Extreme Events and Disasters to Advance Climate Change Adaptation: A Special Report of Working Groups I and II of the Intergovernmental Panel on Climate Change (eds Field, C. B. et al.) 109-230 (IPCC, Cambridge Univ. Press, 2012).

13. Tilloy, A., Malamud, B. D., Winter, H. \& Joly-Laugel, A. A review of quantification methodologies for multi-hazard interrelationships. Earth-Sci. Rev. 196, 102881 (2019).

14. Pescaroli, G. \& Alexander, D. Understanding compound, interconnected, interacting, and cascading risks: a holistic framework. Risk Anal. 38, 2245-2257 (2018).

Differentiates among four types of complex risk related to physical systems and describes some of the key challenges that these pose for the goals of the Sendai Framework for Disaster Risk Reduction.

15. Sadegh, M. et al. Multihazard scenarios for analysis of compound extreme events. Geophys. Res. Lett. 45, 5470-5480 (2018).

16. Gallina, V. et al. A review of multi-risk methodologies for natural hazards: consequences and challenges for a climate change impact assessment. J. Env. Manag. 168, 123-132 (2016).

17. Sendai Framework for Disaster Risk Reduction 2015-2030 Report No. UNISDR/GE/2015 ICLUX EN5000 (United Nations, 2015).

18. Gill, J. C. \& Malamud, B. D. Reviewing and visualizing the interactions of natural hazards. Rev. Geophys. 52, 680-722 (2014).

19. Renn, O., Lucas, K., Haas, A. \& Jaeger, C. Things are different today: the challenge of global systemic risks. J. Risk Res. 22, 401-415 (2017) Proposes that systemic risks-whether financial, climatic or otherwiseshare the characteristics of being global, interconnected, nonlinear and stochastic, and have multiple scales of interaction that can lead to catastrophe.

20. Lloréns, H. Ruin nation. NACLA Report on the Americas 50, 154-159 (2018).

21. Schwartz, E. The facts: Hurricane Maria's effect on Puerto Rico. MercyCorps https://www.mercycorps.org/articles/united-states/hurricane-maria-puertorico (2019).

22. Mazzei, P. \& Robles, F. Former FEMA official accused of taking bribes in Hurricane Maria recovery. New York Times (2019); https://www.nytimes. com/2019/09/10/us/puerto-rico-fema-arrests-corruption.html
23. Clement, S., Zezima, K., Guskin, E., Leaming, W. \& Ribas, J. Puerto Rico after Maria: residents see a failure at all levels of government. Washington Post (2018); https://www.washingtonpost.com/news/national/wp/2018/09/ 12/feature/residents-see-a-failure-at-all-levels-of-government/

24. Santos-Burgoa, C. et al. Differential and persistent risk of excess mortality from Hurricane Maria in Puerto Rico: a time-series analysis. Lancet Planet. Health 2, e478-e488 (2018).

25. Rodriguez, H. in Hurricanes: Climate and Socioeconomic Impacts (eds H. F. Diaz, H. F. \& Pulwarty, R. S.) 121-146 (Springer, 1997).

26. Levermann, A. Make supply chains climate-smart. Nature 506, 27-29 (2014)

27. Johnson, J. \& Gheorghe, A. V. Antifragility analysis and measurement framework for systems of systems. Int. J. Disaster Risk Sci. 4, 159-168 (2013).

28. Helbing, D. Globally networked risks and how to respond. Nature 497, 51-59 (2013).

29. Dilling, L. et al. Is adaptation success a flawed concept? Nat. Clim. Change 9, 570-574 (2019).

30. Introduction to the IRGC Risk Governance Framework, Revised Version (International Risk Governance Center, 2017).

31. Treverton, G. F. et al. Global Food System Stability and Risk: At the Nexus of Defense and Development (Thomson Reuters, 2018)

32. Deryng, D., Conway, D., Ramankutty, N., Price, J. \& Warren, R. Global crop yield response to extreme heat stress under multiple climate change futures. Env. Res. Lett. 9, 034011 (2014).

33. Lucas, R. A. I., Epstein, Y. \& Kjellstrom, T. Excessive occupational heat exposure: a significant ergonomic challenge and health risk for current and future workers. Extr. Physiol. Med. 3, 14 (2014).

34. Iizumi, T. \& Ramankutty, N. How do weather and climate influence cropping area and intensity? Glob. Food Secur. 4, 46-50 (2015).

35. Ben-Ari, T. et al. Causes and implications of the unforeseen 2016 extreme yield loss in the breadbasket of France. Nat. Commun. 9, 1627 (2018).

36. Gaupp, F., Hall, J., Mitchell, D. \& Dadson, S. Increasing risks of multiple breadbasket failure under 1.5 and $2^{\circ} \mathrm{C}$ global warming. Agr. Syst. 175, 34-45 (2019).

37. Kornhuber, K. et al. Amplified Rossby waves enhance risk of concurrent heatwaves in major breadbasket regions. Nat. Clim. Change 10, 48-53 (2020).

38. Singh, D. et al. Climate and the global famine of 1876-78. J. Clim. 31, 9445-9467 (2018).

39. Anderson, W. B., Seager, R., Baethgen, W., Cane, M. \& You, L. Synchronous crop failures and climate-forced production variability. Sci. Adv. 5, eeaw1976 (2019)

40. Tigchelaar, M., Battisti, D. S., Naylor, R. L. \& Ray, D. K. Future warming increases probability of globally synchronized maize production shocks. Proc. Natl Acad. Sci. USA 115, 6644-6649 (2018).

41. Berghuijs, W. R., Harrigan, S., Molnar, P., Slater, L. J. \& Kirchner, J. W. The relative importance of different flood-generating mechanisms across Europe. Water Resour. Res. 55, 4582-4593 (2019).

42. Namias, J. Some meteorological aspects of drought, with special reference to the summers of 1952-54 over the United States. Mon. Weather Rev. 83, 199-205 (1955).

43. Bender, J., Wahl, T., Müller, A. \& Jensen, J. A multivariate design framework for river confluences. Hydrol. Sci. J. 61, 471-482 (2015)

44. Ward, P. J. et al. Dependence between high sea-level and high river discharge increases flood hazard in global deltas and estuaries. Environ. Res Lett. 13, 084012 (2018).

45. Moftakhari, H. R., Salvadori, G., AghaKouchak, A., Sanders, B. F. \& Matthew, R. A. Compounding effects of sea level rise and fluvial flooding. Proc. Natl Acad. Sci. USA 114, 9785-9790 (2017).

46. Serinaldi, F. \& Kilsby, C. G. A blueprint for full collective flood risk estimation: demonstration for European river flooding. Risk Anal. 37, 1958-1976 (2017)

47. Rhee, G., Salazar, J. \& Grigg, C. How long does a 15 -year drought last? On the correlation of rare events. J. Clim. 32, 1345-1359 (2019).

48. Bagley, J. E., Desai, A. R., Harding, K. J., Snyder, P. K. \& Foley, J. A. Drought and deforestation: has land cover change influenced recent precipitation extremes in the Amazon? J. Clim. 27, 345-361 (2014).

49. Cook, B. I., Miller, R. L. \& Seager, R. Amplification of the North American "Dust Bowl" drought through human-induced land degradation. Proc. Natl Acad. Sci. USA 106, 4997-5001 (2009).

50. Otkin, J. A. et al. Flash droughts: A review and assessment of the challenges imposed by rapid-onset droughts in the United States. Bull. Amer. Meteorol. Soc. 99, 911-920 (2018).

51. Overpeck, J. T. The challenge of hot drought. Nature 503, 350-351 (2013).

52. Vogel, M. M. et al. Regional amplification of projected changes in extreme temperatures strongly controlled by soil moisture-temperature feedbacks. J. Geophys. Res. Atmos. 44, 1511-1519 (2017).

53. Salvadori, G. \& de Michele, C. Multivariate multiparameter extreme value models and return periods: A copula approach. Water Resour. Res. 46, w10501 (2010). 
54. Wahl, T., Jain, S., Bender, J., Meyers, S. \& Luther, M. Increasing risk of compound flooding from storm surge and rainfall for major US cities. Nat. Clim. Change 5, 1093-1097 (2015).

55. Zscheischler, J. \& Seneviratne, S. I. Dependence of drivers affects risks associated with compound events. Sci. Adv. 3, e1700263 (2017).

56. Di Baldassarre, G. et al. Water shortages worsened by reservoir effects Nat. Sustain. 1, 617-622 (2018).

57. Greve, P. et al. Global assessment of water challenges under uncertainty in water scarcity projections. Nat. Sustain. 1, 486-494 (2018).

58. Welch, H. L. \& Barnes, K. K. Streamflow Characterization and Summary of Water-quality Data Collection During the Mississippi River flood, April through July 2011. Report No. 2013-1106 (U. S. Department of the Interior and U. S. Geological Survey, 2013); http://pubs.usgs.gov/of/2013/1106/

59. Torres, J. M. et al. Characterizing the hydraulic interactions of hurricane storm surge and rainfall-runoff for the Houston-Galveston region. Coast Eng. 106, 7-19 (2015).

60. Di Baldassarre, G. et al. Sociohydrology: scientific challenges in addressing the sustainable development goals. Water Resour. Res. 55, 6327-6355 (2019). Defines 'sociohydrology' as linking physical and technical approaches to water management with societal dimensions such as power dynamics, culture and psychology, and describes how the latter result in suboptimal decision-making for a wide spectrum of hydrological challenges.

61. Schulz, A. \& Northridge, M. E. Social determinants of health: implications for environmental health promotion. Health Educ. Behav. 31, 455-71 (2004)

62. Gasparrini, A. et al. Mortality risk attributable to high and low ambient temperature: a multicountry observational study. Lancet 386, 369-375 (2015).

63. English, P. B. \& Richardson, M. Components of population vulnerability and their relationship with climate-sensitive health threats. Curr. Env. Health Rep. 3, 91-98 (2016).

64. Schnell, J. L. \& Prather, M. P. Co-occurrence of extremes in surface ozone, particulate matter, and temperature over eastern North America. Proc. Natl Acad. Sci. USA 114, 2854-2859 (2017).

65. Baldwin, J. W., Dessy, J. B., Vecchi, G. A. \& Oppenheimer, M. Temporally compound heat wave events and global warming: an emerging hazard. Earth's Future 7, 411-427 (2019).

66. Matthews, T., Wilby, R. L. \& Murphy, C. An emerging tropical cyclone-deadly heat compound hazard. Nat. Clim. Change $\mathbf{9}$, 602-606 (2019).

67. Storm, I., den Hertog, F., Van Oers, H. \& Schuit, A. J. How to improve collaboration between the public health sector and other policy sectors to reduce health inequalities? - a study in sixteen municipalities in the Netherlands. Int. J. Equity Health 15, 97 (2016).

68. Sisco, S. et al. The role and function of the Liaison Officer: lessons learned and applied after Superstorm Sandy. Health Secur. 17, 109-116 (2019).

69. Abramson, D. M. \& Redlener, I. Hurricane Sandy: lessons learned. Disast. Med. Publ. Health Prepared. 6, 328-330 (2012).

70. Ebi, K. et al. Stress testing the capacity of health systems to manage climate change-related shocks and stresses. Int. J. Env. Res. Public Health 15 2370 (2018).

71. Woo, G. Counterfactual disaster risk analysis. Variance 10, 279-291 (2016).

72. Moftakhari, H. \& AghaKouchak, A. Increasing exposure of energy infrastructure to compound hazards: cascading wildfires and extreme rainfall. Env. Res. Lett. 14, 104018 (2019)

73. Litman, T. Lessons from Katrina and Rita: what major disasters can teach transportation planners. J. Transport. Eng. 132, 11-21 (2006).

74. Marks, D. The urban political ecology of the 2011 floods in Bangkok: the creation of uneven vulnerabilities. Pacific Affairs 88, 623-652 (2015).

75. Martius, O., Pfahl, S. \& Chevalier, C. A global quantification of compound precipitation and wind extremes. Geophys. Res. Lett. 43, 7709-7717 (2016).

76. Jongman, B. et al. Increasing stress on disaster-risk finance due to large floods. Nat. Clim. Change 4, 264-268 (2014).

77. Holzheu, T. \& Turner, G. The natural catastrophe protection gap: measurement, root causes and ways of addressing underinsurance for extreme events. The Geneva Papers on Risk and Assurance 43, 37-71 (2018).

78. Weather, Climate and Catastrophe Insight: 2019 Annual Report (Aon, 2020); http://thoughtleadership.aon.com/Documents/20200122-if-natcat2020.pdf

79. Golnaraghi, M. et al. Managing Physical Climate Risk: Leveraging Innovations in Catastrophe Risk Modelling (The Geneva Association, 2018). Describes the state of the art in assessing risks from climate hazards from the perspective of the insurance sector, including an overview of current initiatives and future objectives.

80. Haasnoot, M., Kwakkel, J. H., Walker, W. E. \& ter Maat, J. Dynamic adaptive policy pathways: a method for crafting robust decisions for a deeply uncertain world. Glob. Environ. Change 23, 485-498 (2013).

81. Hall, J. W., Lempert, R. J., Keller, K., Hackbarth, A., Mijere, C. \& McInerney, D. J. Robust climate policies under uncertainty: a comparison of robust decision making and info-gap methods. Risk Anal. 32, 1657-1673 (2012).
82. Shepherd, T. G. et al. Storylines: an alternative approach to representing uncertainty in physical aspects of climate change. Clim. Change 151, 555-571 (2012).

Advocates for the usage of a non-quantitative 'storyline' approach for analysing very rare or unprecedented event sequences to aid in pinpointing sources of uncertainty and in deepening understanding of climate risks in light of specific decision parameters.

83. Brönnimann, S., Martius, O., Rohr, C., Bresch, D. N. \& Lin, K. E. Historical weather data for climate risk assessment. Ann. NY Acad. Sci. 1436, 121-137 (2019).

84. Wilby, R. L., Dawson, C. W., Murphy, C., O'Connor, P. \& Hawkins, E. The statistical down-scaling model - decision centric (SDSM-DC): conceptual basis and applications. Clim. Res. 61, 259-276 (2014).

85. Prudhomme, C., Wilby, R. L., Crooks, S., Kay, A. L. \& Reynard, N. S. Scenario-neutral approach to climate change impact studies: application to flood risk. J. Hydrol. 390, 198-209 (2010).

86. Moss, R. H. et al. Hell and high water: practice-relevant adaptation science. Science 342, 696-698 (2013).

87. Meadow, A. M. et al. Moving toward the deliberate coproduction of climate science knowledge. Weather Clim. Soc. 7, 179-191 (2015).

88. Weaver, C. P. et al. From global change science to action with social sciences. Nat. Clim. Change 4, 656-660 (2014)

89. Sanders, B. F. et al. Collaborative modeling with fine-resolution data enhances flood awareness, minimizes differences in flood perception, and produces actionable flood maps. Earth's Future 7, e2019ef001391 (2020).

90. Purdy, A. J. et al. Designing drought indicators. Bull. Amer. Meteorol. Soc. 100, 2327-2342 (2019)

Highlights a project to reimagine metrics for the multi-variable hazard of drought through detailed decision-maker engagement and iterative co-production of knowledge.

91. Thonicke, K. et al. Advancing the understanding of adaptive capacity of socio-ecological systems to absorb climate extremes. Earth's Future 8, e2019ef001221 (2020)

92. Beckage, B. et al. Linking models of human behaviour and climate alters projected climate change. Nat. Clim. Change 8, 79-84 (2018).

93. Burger, M., Wentz, J. \& Horton, R. The law and science of climate change attribution. Columbia J. Environ. Law 45, 57-240 (2020).

94. Norström, A. V. et al. Principles for knowledge co-production in sustainability research. Nat. Sustain. 3, 182-190 (2020).

95. Hartley, K., Kuecker, G. \& Woo, J. J. Practicing public policy in an age of disruption. Policy Design Pract. 2, 163-181 (2019).

96. Kumar, R. et al. Dominant control of agriculture and irrigation on urban heat island in India. Sci. Rep. 7, 14054 (2017).

97. Balch, J. K. et al. Switching on the big burn of 2017. Fire 1, 17 (2018) Summarizes the mix of anthropogenic and natural factors that contributed to the severe 2017 Western US fire season and concludes that the combination of physical preconditions with increasing societal exposure call for a well-thought-through set of policy changes.

98. Marlon, J. R. et al. Long-term perspective on wildfires in the western USA. Proc. Natl Acad. Sci. USA 109, E535-E543 (2017).

99. Zhong, S. et al. Urbanization-induced urban heat island and aerosol effects on climate extremes in the Yangtze River Delta region of China. Atm. Chem. Phys. 17, 5439-5457 (2017).

100. Lentz, E. E. et al. Evaluation of dynamic coastal response to sea-level rise modifies inundation likelihood. Nat. Clim. Change 6, 696-701 (2016).

101. Temmerman, S. et al. Ecosystem-based coastal defence in the face of global change. Nature 504, 79-84 (2013).

102. Sadegh, M., Ragno, E. \& AghaKouchak, A. Multivariate copula analysis toolbox (MvCAT): describing dependence and underlying uncertainty using a Bayesian framework. Water Resour. Res. 53, 5166-5183 (2017).

103. Donges, J. F., Schleussner, C.-F., Siegmund, J. F. \& Donner, R. V. Event coincidence analysis for quantifying statistical interrelationships between event time series. Eur. Phys. J. Special Topics 225, 471-487 (2016)

104. Boers, N. et al. Complex networks reveal global pattern of extreme-rainfall teleconnections. Nature 566, 373-390 (2019).

105. Maher, N. et al. The Max Planck Institute Grand Ensemble: enabling the exploration of climate system variability. J. Adv. Model. Earth Syst. 11, 2050-2069 (2019)

106. Lee, C.-Y., Tippett, M. K., Sobel, A. H. \& Camargo, S. J. An environmentally forced tropical cyclone hazard model. J. Adv. Model. Earth Sys. 10, 233-241 (2018).

107. Emanuel, K. Climate and tropical cyclone activity: a new model downscaling approach. J. Clim. 19, 4797-4802 (2006).

108. Lemoine, D. \& Kapnick, S. A top-down approach to projecting market impacts of climate change. Nat. Clim. Change 6, 51-57 (2016).

109. Zeff, H. B., Herman, J. D., Reed, P. M. \& Characklis, G. W. Cooperative drought adaptation: integrating infrastructure development, conservation, and water transfers into adaptive policy pathways. Water Resour. Res. 52, 7327-7346 (2016) 
110. Rivera, F. I. Cultural mechanisms in the exchange of social support among Puerto Ricans after a natural disaster. Qual. Health Res. 22, 801-809 (2012).

111. Emanuel, K. Assessing the present and future probability of Hurricane Harvey's rainfall. Proc. Natl Acad. Sci. USA 114, 12681-12684 (2017).

112. Biesbroek, R. et al. Opening up the black box of adaptation decision-making. Nat. Clim. Change 5, 493-494 (2015).

Emphasizes that decision-making is properly understood as a messy, iterative process, and that collaboration-building efforts must first recognize the diverse mandates and incentives of all actors involved.

113. Wong-Parodi, G., Krishnamurti, T., Davis, A., Schwartz, D. \& Fischhoff, B. A decision science approach for integrating social science in climate and energy solutions. Nat. Clim. Change 6, 563-570 (2016).

\section{Acknowledgements}

This paper was developed from ideas discussed at a May 2019 workshop at Columbia University, organized by C.R., R.M.H., J.Z., O.M., A.A., S.J.C., M.O., A.C.R., T.W., N. Diffenbaugh, S. I. Seneviratne and A. Sobel (http://extremeweather.columbia.edu/ workshop-on-correlated-extremes/). The workshop drew generous support from the U.S. National Science Foundation's Prediction of and Resilience against Extreme Event (PREEVENTS) program, Aon, the Columbia University Initiative on Extreme Weather and Climate, NOAA's Consortium for Climate Risk in the Urban Northeast (CCRUN), the World Climate Research Programme's (WCRP) Grand Challenge on Weather and Climate Extremes, and the European COST Action 'Understanding and modeling compound climate and weather events' (DAMOCLES; CA17109). A portion of C.R.'s work was carried out at the Jet Propulsion Laboratory, California Institute of Technology, under a contract with the National Aeronautics and Space Administration. R.M.H acknowledges support from the NOAA RISA Program (grant no. NA15OAR4310147). J.Z. acknowledges financial support from the Swiss National Science Foundation (Ambizione grant no. 179876). O.M. acknowledges financial support from the Swiss National Science Foundation (grant no. 178751). T.W. acknowledges financial support from the National Science Foundation (grant no. AGS-1929382).

\section{Author contributions}

C.R., R.M.H., J.Z. and O.M. developed the initial concept. C.R. created figures and S.G.B. provided data for Fig. 2. C.R. led the writing of the manuscript, and all authors contributed to writing and editing.

\section{Competing interests}

The authors declare no competing interests.

\section{Additional information}

Correspondence should be addressed to C.R.

Peer review information Nature Climate Change thanks Franziska Gaupp, Silvia Torresan, Gabrielle Wong-Parodi and the other, anonymous, reviewer(s) for their contribution to the peer review of this work.

Reprints and permissions information is available at www.nature.com/reprints. Publisher's note Springer Nature remains neutral with regard to jurisdictional claims in published maps and institutional affiliations.

(๑) Springer Nature Limited 2020 